\title{
Biarlah Gereja Menjadi Gereja (Perenungan terhadap proses pemilihan kepemimpinan Sinode GPM). Oleh
}

\author{
(Pdt. Dr. Henky H. Hetharia, M.Th)
}

\section{Usia 80 tahun GPM: Biarlah gereja menjadi gereja.}

"Let the Church be the Church", (biarlah Gereja menjadi Gereja) merupakan sebuah frase kalimat yang mengemuka sewaktu berlangsungnya Konferensi Misi dan Penginjilan Sedunia di Athena (Yunani, 2005). Frase ini mengandung pengertian bahwa Gereja sebagai salah satu entitas yang ada di dunia dengan hakikat dan karakternya yang khas, yang berbeda dengan entitas lainnya di dunia ini. Gereja, sebagai mana pesan Yesus, Sang Kepala Gereja, hendaknya menjadi suatu entitas yang berada di dalam dunia tetapi tidak berasal dari dunia (Yoh. 15:19). Gereja memang berada di dalam dunia, dan terus bergumul dengan berbagai persoalan di dunia ini, persoalan di dalam dirinya maupun di luar dirinya. Namun, dalam pergumulannya tersebut, Gereja mesti menyadari dan tetap terikat pada hakikat yang khas, yang berbeda dengan entitas lainnya di dunia ini. Gereja harus tampil beda di dunia ini, dan ini hanya bisa terjadi jika Gereja mau dan mampu berdiri di atas dasar dan kehendak Allah di dalam Kristus Yesus.

Ketika Gereja Protestan Maluku (GPM) memasuki dan merayakan ulang tahun ke-80 (6 September 2015), frase "Biarlah Gereja (tetap) menjadi Gereja" ini kembali mengemuka, dan dijadikan sebagai tema khotbah mingguan, ibadah unit maupun wadah/organisasi di seluruh GPM. Pada khotbah minggu tgl. 6 September yang bertepatan dengan HUT GPM, tema biarlah gereja menjadi gereja, melalui bacaan Alkitab menasihati kita untuk hidup di jalan Kristus; tgl 13 September: tema biarlah gereja menjadi gereja, melalui bacaan Alkitab menekankan bahwa para pemimpin (gereja dan masyarakat) semestinya menjadi pelayan dan hamba; tgl 20 September: tema biarlah gereja menjadi gereja, melalui bacaan Alkitab mengharapkan agar semua kita tetap taat dan setia kepada Kristus; dan tgl 27 September: tema biarlah gereja menjadi gereja, melalui bacaan Alkitab menekankan misi gereja di dunia ini. Tema "biarlah Gereja menjadi Gereja" ini mendapatkan kuota waktu pendalaman yang cukup lama, selama 1 bulan (4 minggu) binaan, menegaskan pentingnya tema ini bagi GPM, apalagi bersamaan dengan ulang tahun ke 80 GPM (8 Dekade GPM). Hal ini tidak hanya dimaksudkan sebagai slogan khotbah, tetapi menegaskan kesadaran dan dorongan agar GPM bisa menyadari dirinya sebagai gereja, tubuh Kristus yang ada di dunia ini, GPM hendaknya kembali kepada hakikatnya dalam bergereja, dalam berbagai aspeknya: institusinya, pemimpin dan pelayannya, maupun umatnya. GPM sebagai institusi gerejawi yang telah eksisis dan mandiri selama 80 tahun di bumi Maluku (dan Maluku Utara), dengan menggunakan frase "biarlah gereja (tetap) menjadi gereja" sebagai tema binaan di bulan September ini, hendak mengingatkan dan mengarahkan kehidupan warganya untuk kembali kepada hakikatnya sebagai gereja yang berdasarkan pada kehendak Kristus. Seluruh kehidupan umat dan pelayan, dalam hal ini mestilah diletakkan di bawah kehendak Allah di dalam Kristus Yesus yang diberitakan di dalam Alkitab.

\section{Hakikat GPM sebagai Gereja.}

GPM memiliki hakikat yang sama dengan organisasi gereja lainnya sebagai perwujudan tubuh Kristus di dunia ini, yakni sebagai persekutuan orang percaya yang dipanggil keluar oleh Allah (Eklesia). Gereja, sebagaimana ditegaskan oleh Eka Darmaputera, adalah persekutuan di dalam dan dengan Kristus (Sinaga, dkk. 2005). Persekutuan di dalam dan dengan Kristus inilah yang menjadi hakikat dan identitas Gereja di dunia ini, termasuk GPM. Hakikat GPM sebagai 
persekutuan orang percaya kepada Tuhan Yesus Kristus ini, juga ditegaskan di dalam Tata Gereja GPM (TAP Sinode GPM no: 09/SND/36/2010, Bab I, psl. 1, ay. 1). Hakikat GPM sebagai gereja bukanlah pada kemegahan sarana fisiknya, kuatnya institusi dan organisasi gerejawi, ataupun pada struktur kepemimpinan yang kuat dari aras sinode, klasis hingga jemaat, namun pada seluruh kehidupan persekutuan umatnya (warga jemaat dan pelayan) yang didasarkan pada kehendak Kristus. Hakikat GPM sebagai gereja sebagaimana ditegaskan oleh Paulus: "...hendaklah hidupmu tetap di dalam Dia. Hendaklah kamu berakar di dalam Dia dan dibangun di atas Dia..." (Kol. 2:6,7). Hakikat GPM sebagai gereja ini barulah terlihat ketika kehidupan umatnya (warga jemaat dan pelayan) berdasarkan kepada kehendak Kristus, Sang Kepala Gereja, dan memberlakukan kehendak tersebut dalam seluruh aspek kehidupannya, baik dalam relasi dengan Tuhan, sesama manusia maupun alam ciptaan Tuhan.

Hakikat GPM sebagai gereja, merupakan persekutuan orang percaya, dipanggil ke luar oleh Allah untuk masuk ke dalam dunia, berkarya dengan menghadirkan tanda-tanda kerajaan Allah di dalam dunia ini. GPM sebagai gereja hadir di dunia bukan untuk dirinya sendiri, tetapi dipanggil keluar dan masuk ke dalam dunia, melaksanakan fungsi dan perannya sebagai Garam dan Terang bagi dunia ini (Mat. 5:13-16) maupun sebagai Surat Kristus (2 Kor. 3:3) yang terbuka bagi dunia ini. Namun, sebelum GPM ke luar dan masuk ke dalam dunia untuk melaksanakan fungsinya tersebut, ia haruslah terlebih dulu membarui dan membenahi dirinya agar sesuai dengan kehendak Krisuts, Sang Kepala Gereja. GPM yang memiliki spirit reformasi, tentu harus terus berada dalam proses-proses perbaikan dan pembaruan hidupnya agar dapat berfungsi sebagai Garam, Terang dan sebagai Surat Kristus yang terbuka bagi dunia ini. GPM sebagai gereja beraliran reformis, tentu menganut dan menerapkan prinsip: ecclesia reformata semper reformanda (gereja yang dibarui dan selalu membarui dirinya), sehingga proses membarui dirinya sesuai dengan kehendak Kristus, terus berlangsung selama GPM masih eksis di dunia ini. Prinsip perbaikan dan pembaruan GPM sebagai gereja tersebut merupakan prinsip Alkitabiah sebagaimana ditegaskan Paulus: "Janganlah kamu menjadi serupa dengan dunia ini, tetapi berubahlah oleh pembaharuan budimu..." (Rm. 12:2). GPM dituntut untuk memahami dan melaksanakan kehendak Allah di dalam Alkitab untuk terus membarui dirinya dalam berbagai aspek: baik umat, pelayan maupun institusi/lembaga. Salah satu proses pembaruan yang mesti dilakukan GPM adalah Persidangan Sinode ke XXXVII GPM, di mana salah satu agenda penting dalam persidangan tersebut adalah pemilihan Majelis Pekerja Harian (MPH) Sinode GPM, di samping agenda-agenda penting lainya dalam persidangan Sinode tersebut.

\section{Agenda dan Proses Pemilihan Kepemimpinan (MPH) Sinode GPM.}

Memasuki usia ke 80 tahun (8 dekade) GPM, GPM akan menghadapi dan menjalani salah satu peristiwa gerejawi yang penting, yang menentukan arah perjalanan bergereja ini. peristiwa gerejawi dimaksud adalah pelaksanaan Sidang Sinode GPM ke XXXVII (direncanakan akan berlangsung pada 15 November 2015). Agenda ini tidak terelakkan, karena sistem kepemimpinan GPM sebagai institusi keagamaan bersifat periodik, dan berlangsung selama 5 (lima) tahun. Agenda lima tahunan ini juga memiliki posisi stategis karena melalui agenda ini, akan terpilih kepemimpinan (MPH) Sinode GPM yang akan memimpin dan melayani gereja ini, tidak hanya memilih pemimpin para pendeta GPM atau majelis jemaat GPM, tetapi terlebih memilih pemimpin warga jemaat GPM, maupun pemimpin institusi keagamaan yang besar dan berpengaruh dalam kehidupan masyarakat Maluku. Semua kita, baik sebagai pendeta, majelis, warga jemaat, pemerintah provinsi maupun agama-agama lainnya di Maluku, terus menantikan hasil pemilihan MPH Sinode oleh persidangan Sinode ini. Pembahasan agenda dan proses 
pemilihan kepemimpinan Sinode GPM di sini, saya tidak akan menyoroti siapa-siapa yang akan menjadi Ketua Sinode, ataupun posisi MPH lainnya, yang untuk menjelang persidangan sinode ini, sedang menjadi sorotan warga jemaat maupun masyarakat di Maluku, dan incaran kebanyakan pihak yang memenuhi persyaratan jabatan-jabatan tersebut, khususnya para pendeta di GPM baik secara individu maupun kelompok (geng?). Saya tidak masuk dalam pembahasan tentang sosok atau figure MPH, agar tidak membangun opini, yang bersifat subjektif dan tendensius terhadap pihak-pihak tertentu. Membarui gereja bukanlah untuk mendapatkan jabatan atau kekuasaan, tetapi dengan membarui sistem-sistem bergereja di GPM yang tidak membangun gereja sebagai tubuh Kristus, sistem-sistem bergereja yang harus terus dibarui agar GPM sebagai gereja tetap menjadi gereja Kristus di dunia ini. Karena itu, saya cenderung memberi perenungan sepintas lalu terhadap proses pemilihan kepemimpinan (MPH) Sinode GPM yang telah berlangsung di periode-periode yang lalu dan akan berlangsung nanti di akhir tahun ini.

Pemilihan MPH Sinode oleh peserta biasa persidangan Sinode, telah diatur di dalam Peraturan Pokok GPM tentang Sinode (TAP SINODE GPM no: 09/SND/36/2010, pasal 7 \& 8), bahwa yang memilih MPH Sinode GPM adalah peserta biasa persidangan yang terdiri dari MPH Sinode, Ketua Klasis dan Utusan Jemaat melalui Klasis (5 orang Penatua/Diaken dan 2 orang Pendeta/Penginjil). Dengan demikian, yang memiliki hak suara untuk memilih MPH Sinode adalah mereka yang berstatus sebagai MPH Sinode (periode sebelumnya, 9 orang), dan delegasi 32 Klasis (8 orang x 32 klasis), semuanya berjumlah 265 suara. Mereka inilah merupakan "perwakilan" dari 500-an ribu warga jemaat GPM di Maluku dan Maluku Utara. Di atas pundak mereka inilah masa depan GPM untuk 1 periode ke depan (5 tahun) dipertaruhkan. Mereka inilah yang memiliki hak untuk memilih siapa nakhoda yang akan menjalankan dan mengemudikan perjalanan bahtera GPM untuk 5 tahun ke depan. Hal ini mesti diartikan bahwa ke 265 peserta yang akan memilih (voters) tersebut mesti memahami dengan sunguh-sungguh dan penuh perenungan bahwa kepemimpinan Sinode GPM yang akan mereka pilih tersebut, bukanlah menurut pemahaman dan kepentingan mereka semata, hasil pemilihan tersebut dengan semua implikasinya bukanlah untuk kepentingan para voter tersebut.! Mereka yang memiliki hak suara tersebut harus menyadari bahwa seluruh warga jemaat di GPM mempercayakan dan menaruh harapan kepada mereka, mereka diberi hak istimewa untuk memilih para pemimpin GPM yang akan memimpin dan melayani seluruh umat GPM. Karena itu, para voter ini dalam memilih para pemimpin GPM tersebut mesti menyadari dan membuka diri untuk mendengar suara-suara warga jemaat di seluruh GPM, serta masukan-masukan dari masyarakat luas tentang kepemimpinan GPM tersebut. Mereka inilah sesungguhnya para stakeholder GPM yang penting untuk didengar. Mendengar suara umat ini penting bagi para voter karena pada akhirnya para pemimpin GPM tersebut bukan hanya untuk memimpin para voter, tetapi memimpin seluruh warga jemaat GPM. MPH GPM yang terpilih nanti adalah pemimpin sekaligus pelayan bagi seluruh warga jemaat, mereka adalah orang tua dan pengayom bagi seluruh warga jemaat GPM yang plural ini. Warga jemaat sebagai basis dan ujung tombak GPM, merindukan pemimpin GPM seperti apa yang mereka inginkan, sehingga para voter perlu mendengar suara, kerinduan dan harapan warga jemaat tersebut. Sedangkan terbuka untuk mendengar masukan dari masyarakat juga penting, karena kepemimpinan GPM telah menjadi patron kepemimpinan di masyarakat. Visi, pendapat dan suara pemimpin GPM sebagai lembaga moral setidaknya didengar dan ikut mempengaruhi masyarakat luas. Mendengar suara warga jemaat dan masyarakat ini dan mengakomodir suara dan kebutuhan para stakeholder dalam memilih MPH Sinode merupakan langkah bijak para voter untuk menampik sitiran dan identifikasi prof. Watloly dalam Assau edisi sebelumnya (vol.13, no. 6 Juli-Agustus 2015), bahwa iven 
persidangan sinode GPM sebagai sebuah permainan politik kekuasaan, yang menonjolkan tensi "ketegangan saraf politik" antara konstituen politik dan kelompok suksesi, dengan berbagai praktik politik yang terjadi (ritual politik, lobi politik, transaksi politik, tim sukses, dana suksesi, penyumbang dana suksesi, rapat politik, serta jaringan tim sukses dari level jemaat, klasis dan sinode yang semuanya bekerja secara sembunyi-sembunyi (under cover) di balik symbol-simbol organisasi dan kesucian gerejawi. "Ketegangan saraf politik" ini menurut Watloly lebih menonjol dari pada ketegangan saraf pergumulan GPM sebagai representasi seluruh warga GPM. Saya tidak mencoba memberi penilaian terhadap identifikasi Watloly ini, tetapi saya menilai bahwa identifikasi Watloly ini merupakan tantangan bagi para voter. Ada atau tidak adanya apa yang diidentifikasi oleh Watloly ini hanya bisa dijawab atau dibuktikan oleh para voter dalam persidangan sinode ke XXXVII yang akan berlangsung nanti.

\section{GPM harus tampil beda.}

Proses pemilihan MPH Sinode dalam agenda persidangan Sinode GPM telah diatur dalam Tata Gereja GPM bab III pasal 5 huruf e, bahwa tugas dan wewenang persidangan Sinode adalah memilih dan mengangkat MPH Sinode (dan Majelis Pertimbangan MPH Sinode) untuk masa bakti 5 tahun. Proses pemilihan MPH Sinode ini kemudian diatur dalam Peraturan Organik GPM tentang Kriteria dan Tata Cara Pemilihan, di mana setiap peserta biasa (voter) memiliki hak untuk memilih (one man one vote). Proses pemilihan ini tampaknya sama, tidak berbeda dengan proses-proses pemilihan pada sebagian besar organisasi sosial maupun keagamaan. Karena itu, Watloly menyinggung bahwa Persidangan Sinode ini merupakan iven politik GPM karena praktiknya hampir sama, bahkan cenderung foto kopi (exemplaris) dengan iven politik atau iven suksesi lainnya di dalam masyarakat umum. Hal ini menurut saya, tidaklah salah. Proses pemilihan kepemimpinan GPM tidak berbeda dengan proses yang sama di masyarakat. Namun, jika kemudian Watloly mengidentifikasikan Persidangan Sinode GPM tersebut sebagai iven suksesi politik gerejawi yang kotor dan kasar di mana kelompok suksesi yang saling mengintip, saling beradu, dan bertransaksi dalam sebuah ruang persidangan, maka menurut saya hal ini lagi-lagi merupakan tantangan bagi para voter untuk mementahkan identifikasi Watloly dimaksud. Sekali lagi, saya tidak memberi penilaian terhadap apa yang diidentifikasi Watloly tersebut, tetapi hal ini akan dibuktikan sendiri oleh para voter kelak di persidangan sinode nanti.

Saya sendiri mencoba memberikan alternative lain terhadap proses persidangan Sinode GPM tersebut, yang dapat membuat persidangan ini memiliki spirit dan nuansa yang berbeda, walaupun dengan cara yang sama (pemungutan suara oleh voters), sebagai cara yang lazim dan dapat diterima oleh akal sehat di masyarakat (ada yang mengusulkan lewat undian). Spirit yang berbeda tersebut adalah seluruh warga GPM, khususnya para voter mesti memaknai dengan sadar bahwa peristiwa pemilihan MPH Sinode tersebut bukanlah suatu iven politik yang penuh "ketegangan saraf politik" (identifikasi Watloly), tetapi merupakan suatu perhelatan iman untuk memilih pemimpin GPM ke depan. Spirit yang khas gerejawi dibalik peristiwa ini adalah Tuhan, Sang Kepala Gereja, yang menggunakan dan menggerakan para voter ini untuk memilih pemimpin gereja-Nya ini. Karena itu para voter tidak bisa memahami proses ini sebagai iven politik, tetapi sebagai peristiwa ketika Tuhan yang punya gereja ini, menggunakan cara yang manusiawi dan rasional untuk memilih para pemimpin gereja-Nya. Spirit inilah yang menyadarkan kita untuk memulai proses pemilihan MPH dengan suatu ibadah, sebagai mana ditegaskan dalam tata cara pemilihan selama ini. Ibadah ini tentu bukanlah sebuah lipservice atau upaya menutup iven politik di balik kesucian ibadah, tetapi sungguh-sungguh agar para voter membuka diri terhadap campur tangan Tuhan yang punya GPM ini. Kesadaran ini sesungguhnya 
telah ditegaskan dalam peraturan GPM tentang tata cara pemilihan, di mana salah satu azas pemilihan yakni azas ketaatan, yang mengutamakan prinsip taat dan setia kepada Firman Allah sebagaimana disaksikan dalam Kisah Para Rasul 1:24 "Mereka semua berdoa dan berkata ya Tuhan, Engkaulan yang mengenal hati semua orang, tunjukkanlah siapa yang Engkau pilih". Bagaimana kenyataannya? Para voter sendiri-lah yang akan membuktikan kebenaran spirit dan azas pemilihan ini.

Nuansa yang berbeda juga seharusnya ditampilkan oleh GPM pada persidangan ini. Proses pemilihan kepemimpinan GPM bukan hanya hajatan atau peristiwa yang melibatkan para peserta Sidang Sinode, khususnya para voter, tetapi juga adalah hajatan dan peristiwa yang "melibatkan" seluruh warga GPM. Seluruh warga jemaat yang tidak mengikuti Sidang Sinode seharusnya juga mendapat "ruang untuk terlibat" dalam proses pemilihan dimaksud. Kesadaran untuk melibatkan umat ini penting dibangun karena memiliki dasar teologis, yaitu hakikat GPM sebagaimana ditegaskan di depan adalah persekutuan orang percaya (jemaat). Jemaat adalah kekuatan GPM sehingga penting untuk diberi ruang. "Ruang untuk terlibat" bagi seluruh jemaat GPM ini, menurut saya dapat diaktualkan melalui peritiwa doa bersama yang dilakukan oleh seluruh pelayan dan warga jemaat di dalam gereja masing-masing jemaat, pada waktu yang ditentukan menjelang proses pemilihan oleh para voter di tempat persidangan Sinode. Seluruh umat dan pelayan GPM di setiap jemaat, diiringi dentangan lonceng gereja pada waktu yang telah ditentukan secara bersamaan di seluruh jemaat-jemaat GPM, menaikan doa khusus kepada Sang Kepala Gereja untuk menyucikan, menguasai dan menuntun para voter yang juga sedang berdoa di tempat persidangan, untuk pada waktunya menentukan pilihannya dalam tuntunan dan kehendak Sang Kepala Gereja. Nuansa ini dapat menampilkan wajah GPM sebagai institusi moral yang sungguh-sungguh terbuka untuk dituntun oleh Roh Tuhan untuk terus mengalami pembaruan agar menjadi gereja yang dikehendaki Kristus, gereja yang tampil beda untuk menerangi dan menggarami dunia ini. Bagaimanapun, cara yang benar akan memberikan hasil yang benar pula.! 